\title{
Statyba
}

\section{THE ANALYSIS OF SPEED AND PRESSURE OF WIND IN RAINY WEATHER}

\section{Paukštys \& V. Stankevičius}

To cite this article: V. Paukštys \& V. Stankevičius (2001) THE ANALYSIS OF

SPEED AND PRESSURE OF WIND IN RAINY WEATHER, Statyba, 7:1, 68-72, DOI:

10.1080/13921525.2001.10531701

To link to this article: https://doi.org/10.1080/13921525.2001.10531701

曲 Published online: 30 Jul 2012.

Submit your article to this journal

III Article views: 112 


\title{
VĖJO SLĖGIO IR JO GREIČIO KITIMO LYJANT ANALIZE்
}

\author{
V. Paukštys ${ }^{1}$, V. Stankevičius ${ }^{2}$ \\ 'Kauno technologijos universitetas, \\ ${ }^{2}$ Architektūros ir statybos institutas
}

\section{Ivadas}

Oro judejjimą gamtoje - vèją sužadina slègiu skirtumai tarp skirtingų atmosferos zonų, kurių pasiskirstymas priklauso nuo ìvairių Žemès rajonu šiluminès būsenos. Atmosferos zony tarpusavio padètis ir slègiụ kritimo trajektorija nusako vèjo kryptí, o slègių skirtumas - vèjo greiti. Be to, vèjo greitis ir kryptis labai priklauso ne tik nuo bendrosios atmosferos cirkuliacijos, bet ir nuo vietovès reljefo.

Vèjo poveikis pastatų eksploatavimui gali būti teigiamas, nes jis vèdina, džiovina, vessina arba šildo, trukdo vésiam nakties orui pasiekti žemès paviršiu, ir neigiamas, nes jis neša dūmus ir kvapus, ipučia $i$ atitvaras ir medžiagas vandeni, atšaldo konstrukciju paviršių, dèl jo per laidžias konstrukcijas arba jụ sandūras oras patenka i patalpas ar išeina iš ju, pripusto sniego, veikia, kartais griaunančia jèga, pastatus, statinius ir laikančiąsias konstrukcijas [1].

Oro judejjimo apie pastatus problemas Lietuvoje intensyviai pradeta spręsti 1960-1970 metais. Pagrindiniai tyrimu tikslai buvo nustatyti oro srautus apie pastată o gauti duomenys dažniausiai buvo naudojami projektuojant ir statant aukštus pastatus, gamyklas, elektros linijas.

Projektuojant statinius reikia žinoti: vejjų kartojimąsi (procentais) pagal pasaulio šaliụ kryptis (rumbus); vidutini veju greitị ivairiu metu laiku; vyraujančią vejju krypti sezonais ir mẻnesiais; vyraujantị vẻju greiti ivairiomis kryptimis ir metų laikais; vèju trukmę ir kartojimąsi pagal jụ greitị; didžiausią vèjụ greiti per tam tikra periodą -1 metus, $5,10,15$ ir 20 metu.

Tačiau nepakanka tirti vien tik vejjo poveiki pastatu konstrukcijoms, kadangi išorinius pastatu paviršius veikia ne tik vèjas, bet ir lietus. Didelè dalis lietaus patenka ant atitvarų išorinio paviršiaus, skverbiasi gilyn ir ardo atitvaros paviršiaus sluoksnio medžiagą. Lietus prateka per atitvavarines konstrukcijas, ju paviršini sluoksni dèl prastos surenkamujų elementu kokybès ir netinkamo transportavimo, del to, kad jie netiksliai sumontuojami, nepakankamai ivertinamos statybos rajono klimatinès salygos.

Šiuo metu atitvaroms naudojamos naujos daugiasluoksnès statybinès medžiagos, kuriose yra daug montavimo siūliụ, todèl kompleksinis lietaus ir vèjo poveikis joms yra ypač pavojingas.

\section{Tyrimy tikslas}

Atsižvelgiant i tai, kad anksčiau surinkti duomenys apie klimatinių sąlygu kitimą ir atlikti konstrukcijų imirkio lietaus su vèju metu eksperimentiniai tyrimai nepakankamai tiksliai ivertinami tyrimuose ir projektuose, šiu tyrimu tikslas: pagal statistinius klimato duomenis palyginti vidutinius vèjo greičius lyjant ir nelyjant, surinkti trūkstamą statybinès klimatologijos duomenų dalị, kurios reikia atitvarų ilgaamžiškumo problemai spręsti.

\section{Vëjo slėgis ị konstrukcijos paviršių}

Atviroje erdvèje vèjas, sutikęs kliūtị - pastata, statinių grupe, net didesni vandens ar želdynu telkini, ji apteka nevienodai - tai mažindamas greitị ir slègi, tai keisdamas krypti, tai sukeldamas praretinto oro laukus (neigiamas slègis) ar sužadindamas sūkurius. Kartais sūkurinio srauto greitis priešvèjinèje pusèje net kelis kartus gali viršyti skaičiuojamaji vėjo greitị horizontaliojoje plokštumoje. Dèl tos priežasties labai greitai suyra sūkuriụ apiplaunama pastatų apdaila ir jụ elementai.

Lietus pučiant vèjui drékina pastatu atitvaru vertikalius paviršius. Norint prognozuoti pastatu idrèkimo nuo lietaus vertes, reikia žinoti vèjo slègio pasiskirstymą prie pastato fasado. Vejo slègio pasiskirstymo 
atitvariniu konstrukciju paviršiuose tyrimai parodė [2], kad didžiausi teigiami vèjo slègiai susidaro fasaduose, statmenuose vejjo krypčiai.

Statinè apkrova, susidaranti bet kuriame j-ajame konstrukcijos taške, proporcinga oro srauto slègiui ir kūno paviršiaus plotui $S$, statmenam vèjo greičio vektoriui:

$$
\bar{R}_{j}=c_{R} \cdot \frac{\rho \cdot \bar{v}_{j}^{2}}{2 \cdot g} \cdot S
$$

$\bar{R}_{j}$ - statinè apkrova, veikianti j-ajame taške, $\mathrm{kg} ; \rho-$ oro tankis, $\mathrm{kg} / \mathrm{m}^{3} ; S$ - kūno paviršiaus plotas, $\mathrm{m}^{2} ; g-$ laisvojo kritimo pagreitis $\left(g=9,81 \mathrm{~m} / \mathrm{s}^{2}\right) ; c_{R}$ - aerodinaminis koeficientas; $v$ - vidutinis vejo greitis, $\mathrm{m} / \mathrm{s}$.

Vèjo gūsiai, taip pat oro srauto tekejjimo sutrikimai, atsirandantys jiems aptekant gretimai stovinčius pastatus, lemia dinaminių apkrovų dydžius. Apkrovos ir jų sukeliami įtempimai konstrukcijose paprastai ịvertinami kaip papildomos statinès apkrovos, tačiau jas ivertinti yra bütina.

Natūriniai tyrimai [3] parodè, kad vèjo gūsiai sukelia pastatų svyravimus. Nuo šių svyravimų intensyvumo priklauso dinaminiai itempimai, dèl kuriụ gali atsiverti plyšiai sienose ir pablogeti viso pastato eksploatacinès savybès. Skaičiuojant aukštų pastatų patvarumą ivertinant vidutini vèjo greičio kitimą pagal aukštị, kartu reikia jvertinti ir dinamines apkrovas, susidarančias dèl vèjo gūsių.

Pavojingas vèjo greitis gūsio metu, lemiantis dinamines apkrovas, gali būti išreikštas formule:

$$
v_{j}(t)=\frac{\bar{v}_{j}+v_{j}^{\prime}(t)}{2},
$$

$\bar{v}_{j} \quad$ - vidutinis vèjo greitis, $\mathrm{m} / \mathrm{s} ; v_{j}^{\prime}(t)$ - vèjo gūsio greitis, $\mathrm{m} / \mathrm{s} ; v_{j}(t)$ - vidutinis vejjo greitis $(\mathrm{t})$ laiko momentu, $\mathrm{m} / \mathrm{s}$.

Slègis, veikiantis $\mathrm{j}$-ajame taške, jvertinant statines ir dinamines apkrovas, gali būti išreikštas tokia matematine išraiška:

$$
R_{j}(t)=\bar{R}_{j}+R_{j}^{\prime}(t)
$$

$R_{j}^{\prime}(t)$ - dinaminè apkrova, veikianti j-ajame taške, $\mathrm{kg}$; $\bar{R}_{j}$ - statinè apkrova, veikianti j-ajame taške, kg.

Pagrindinis veiksnys, lemiantis slegio $i$ atitvaros paviršių dydi, yra vejo greitis. Tai reiškia, kad net ir dèl nedidelių vèjo greičio apskaičiavimo netikslumu galima gauti dideles susidarančio slègio skirtumų paklaidas. Rei- kia kuo tiksliau nustatyti visus galimus vejjo greičius reikiamame klimatiniame rajone, kad būtų galima tiksliai nustatyti laikančiujų konstrukcijų patvarumą, svyravimų charakteristikas, esant kritiniams vėjo greičiams, ir dar projektavimo stadijoje parinkti patikimiausią konstrukcijos tipa.

Tiriant kompleksini klimato poveiki, t.y. bendrą lietaus ir vejjo ịtaką išoriniụ sluoksniụ drègminiam būviui, kaip rodo [4] tyrimu duomenys, buvo nustatyta, kad viena pagrindinių priežasčių, lemiančių apsauginès apdailos sienutès iš skelto paviršiaus silikatinių plytụ, sumūrytų cemento ir kalkių skiediniu, perdrèkimo trukmę, yra vèjo greitis lyjant.

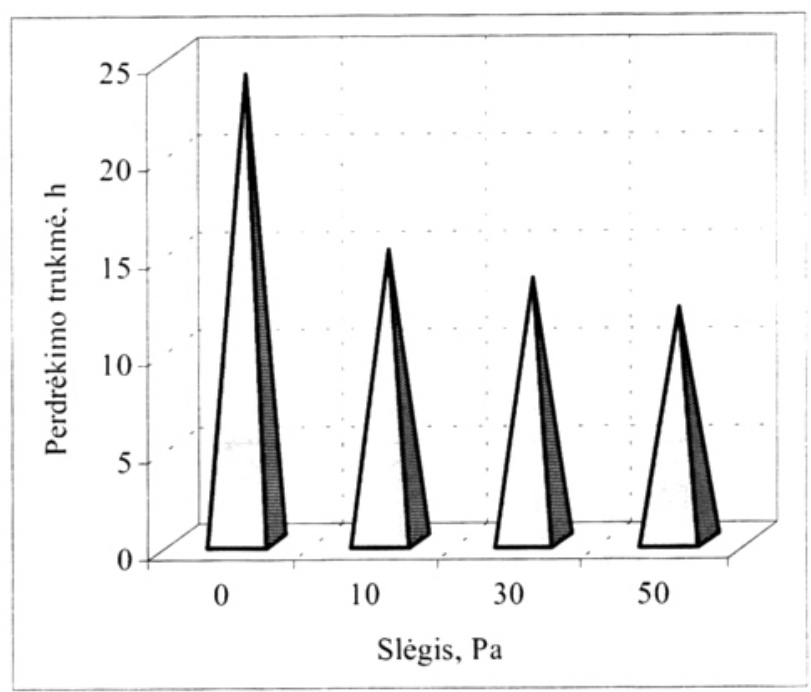

1 pav. Skelto paviršiaus silikatinių plytų mūro su cemento ir kalkiu skiediniu sienutès perdrėkimo trukmés priklausomybé nuo slègio

Fig 1. Dependence of moisture content in sand-lime brick with chipped off surface on cement-lime mortar due to wind pressure

Bandant sumūrytą sienutę, veikiamą lietaus ir vèjo, buvo pastebèta, kad pirmiausia drègmès dèmès kitoje atitvaros pusejje pasirodo ties siūlèmis. Vadinasi, atitvarinių konstrukcijụ pralaidumas dažniausiai susijęs su mazgu konstrukcinėmis ypatybėmis, montavimo kokybe ir rečiau - su pačios atitvaros medžiagu savybèmis. Vanduo kartu su infiltruojamu oro srautu patenka per siūlių plyšius ir nesandarumus. Vèjo slègi didinant nuo 0 iki $50 \mathrm{~Pa}$, sienutès perdrèkimo trukmè sutrumpèja apie 3 kartus.

Dabartinèse statybinèse normose vejjo poveikis vertinamas pagal vidutini jo greiti, neišskiriant vidutinio 
greičio lietui lyjant ir kai nelyja [5]. Kadangi statybinès klimatologijos normose duomenų apie vèjo greitị lyjant nèra, buvo užsibrèžta atlikti statistinę klimatiniu duomenu analizę, kuria būtų nustatyta, kaip pasikeičia vidutinis vejjo greitis lyjant.

\section{Vèjo greičio pokyčių analizè}

Meteorologinèse stotyse horizontalus vejjo greitis metrais per sekundę matuojamas vèjarodžiais arba anemorumbometrais $\mathrm{M}-63 \mathrm{M}-1$, irengtais meteorologijos aikštelèse 10-13 m aukštyje nuo žemès paviršiaus. Anemorumbometras automatiškai išmatuoja $10 \mathrm{~min}$ vidutini vèjo greitị nuo 1 iki $60 \mathrm{~m} / \mathrm{s}$. Pagal pasirinktą metodiką (remiantis archyviniais pastaruju 10 metụ Vilniaus, Kauno ir Klaipedos meteorologinių stebẻjimų duomenimis) buvo lyginamas vèjo greitis lyjant ir kai nelyja: bendras, skirtingais mènesiais ir esant skirtingai vejjo krypčiai.

Vidutiniai vèjo greičiai

Mean wind speeds

\begin{tabular}{|l|c|c|}
\hline \multirow{2}{*}{\multicolumn{1}{|c|}{ Miestas }} & \multicolumn{2}{|c|}{ Vidutinis vėjo greitis, $\mathrm{m} / \mathrm{s}$} \\
\cline { 2 - 3 } & lyjant & kai nelyja \\
\hline Vilnius & 3,66 & 2,92 \\
\hline Kaunas & 4,33 & 3,44 \\
\hline Klaipèda & 5,12 & 3,59 \\
\hline
\end{tabular}

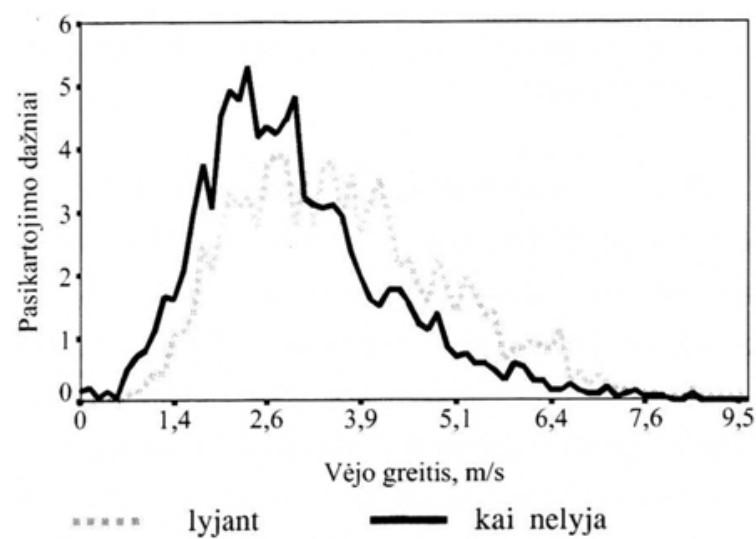

2 pav. Vilniaus miesto vèjo greičio santykinių dažnių histograma

Fig 2. Histogram of wind speed relative frequency for Vilnius

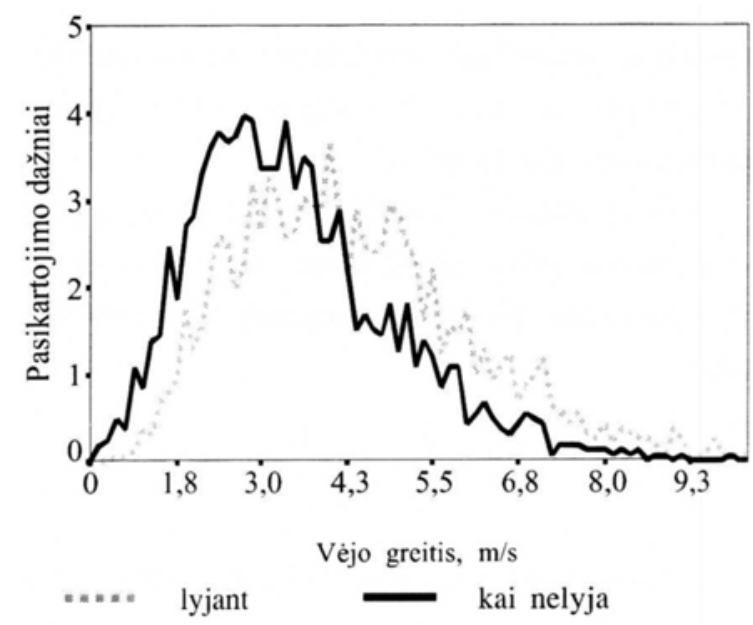

3 pav. Kauno miesto vèjo greičio santykinių dažnių histograma

Fig 3. Histogram of wind speed relative frequency for Kaunas

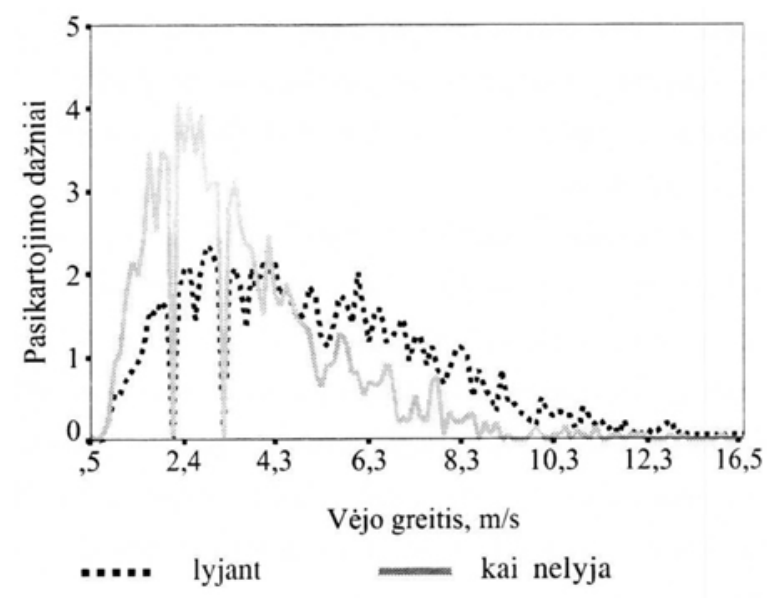

4 pav. Vèjo greičio Klaipédoje santykinių dažnių histograma

Fig 4. Histogram of wind speed relative frequency for Klaipèda

Vidutinio vẻjo greičio padidẻjimas lyjant gali būti apskaičiuotas taip:

$$
\bar{v}_{v i d}=\frac{v_{v i d l}-v_{v i d}}{v_{v i d}} \cdot 100 \%,
$$

$v_{\text {vid }}$ - vidutinis vèjo greitis, kai nelyja, $\mathrm{m} / \mathrm{s} ; v_{\text {vidl }}-$ vidutinis vèjo greitis lyjant, $\mathrm{m} / \mathrm{s} ; \bar{v}_{v i d}-$ vejjo greičio padidejimas, $\%$.

Iš 2,3 ir 4 paveikslụ matome, kad nelyjant dažniausi $2-3 \mathrm{~m} / \mathrm{s}$ vèjo greičiai. Lyjant vèjo greitis dažniausia būna didesnis, palyginti su vèju, kai nelyja.

Palyginę pastaruju 10 metụ vẻjo greičio duomenis gavome, kad Kauno ir Vilniaus miestuose vidutinis 
vèjo greitis lyjant yra apie $26 \%$ didesnis už vejjo greiti, kai nelyja.

Tuo tarpu Klaipèdoje vidutinis vejo greitis padidèja nuo $3,59 \mathrm{~m} / \mathrm{s}$, kai nelyja, iki $5,12 \mathrm{~m} / \mathrm{s}$, kai lyja. Iš gautu rezultatụ matome, kad Klaipèdoje vejjo greitis lyjant yra apie $42 \%$ didesnis už vèjo greitî, kai nelyja.

Be to, iš rezultatụ matome, kad Klaipèdoje $95 \%$ visu vejju lietui lyjant yra silpnesni kaip $10 \mathrm{~m} / \mathrm{s}$ ir tik $5 \%$ veju greitis viršija $10 \mathrm{~m} / \mathrm{s}$. Tuo tarpu Kaune $95 \%$ visu vejų lietui lyjant yra silpnesni kaip $7,4 \mathrm{~m} / \mathrm{s}$, o Vilniuje silpnesni kaip $6,4 \mathrm{~m} / \mathrm{s}$.

Kadangi didžiausius vidutinių vẻjo greičių skirtumus lyjant ir kai nelyja gavome Klaipedos mieste, todèl tolesni teoriniai skaičiavimai atlikti tik Klaipèdos miestui, imant skirtingụ mẻnesiụ ir skirtingų vèjo krypčių duomenis.

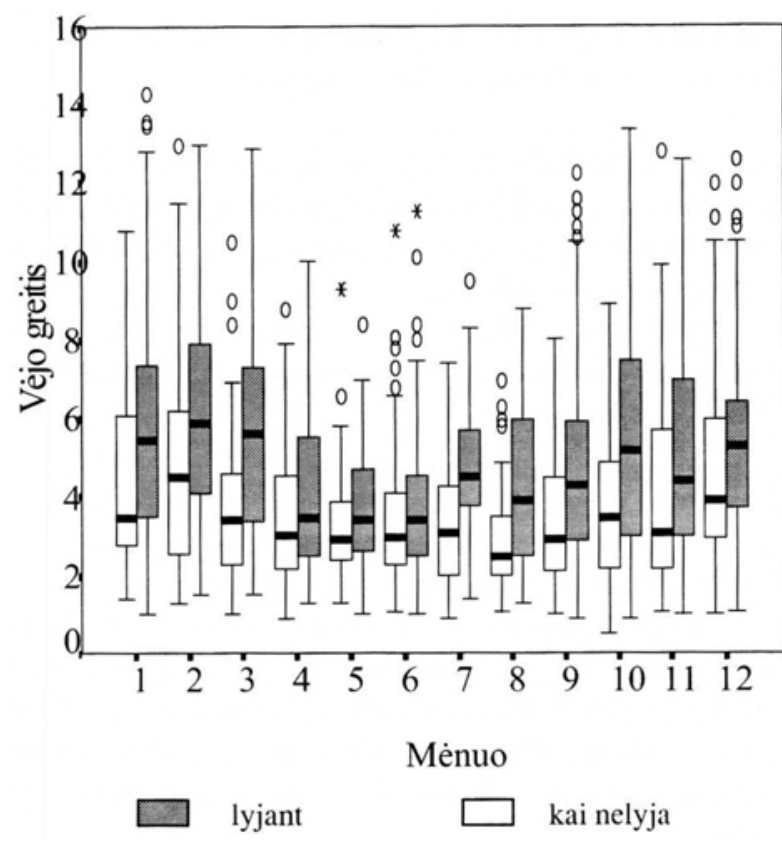

5 pav. Vèjo greičio pasiskirstymas mènesiais Klaipèdoje

Fig 5. Wind speed monthly distribution in Klaipeda

Iš gautụ rezultatụ matome, kad dažniausiai lyja ir stipriausi vejjai pučia rudens ir žiemos ménesiais, pavasarèjant vèjai rimsta, bet darosi nepastovesni. Lyginant vidutinius vejjo greičius lietui lyjant ir kai nelyja, matyti, kad didžiausias skirtumas gautas kovo mènesi. Vidutinis vejo greitis, kai nelyja $3,52 \mathrm{~m} / \mathrm{s}$, tuo tarpu lyjant vidutinis vèjo greitis yra $5,65 \mathrm{~m} / \mathrm{s}$. Palyginę šiuos rezultatus matome, kad vėjo greitis lyjant yra apie $60 \%$ didesnis už vèjo greitị, kai nelyja.

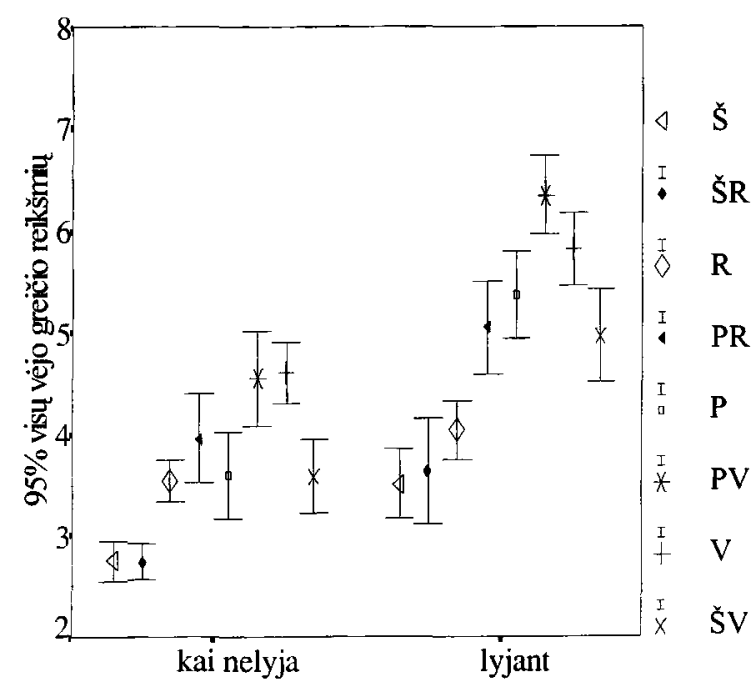

Vèjo kryptys: P - pietų; R - rytų V - vakaru; S šiaurès; PV - pietvakarių; $\check{S} V$ - šiaurès vakarų $\check{S} R$ šiauress rytu; $P R$ - pietryčių

6 pav. Skirtingų krypčių vèjo greičio pasiskirstymas Klaipèdos mieste

Fig 6. Different direction wind speed distribution in Klaipèda

Palyge skirtingụ vèjo krypčiu vidutinius greičius lyjant ir kai nelyja matome, kad lyjant lietui dažniausiai pučia vakaru krypties vejjai, tačiau stipriausi yra pietvakariụ vejai. Palyginę vidutinius vèjo greičius lietui lyjant ir kai nelyja, matome, kad didžiausias skirtumas gautas pučiant pietvakariu krypties vejjams. Vidutinis vèjo greitis, kai nelyja, siekè $4,6 \mathrm{~m} / \mathrm{s}$, tuo tarpu lietui lyjant vidutinis vèjo greitis siekè $6,35 \mathrm{~m} / \mathrm{s}$. Palyginus šiuos rezultatus gauta, kad vejo greitis lyjant yra apie $38 \%$ didesnis už vejjo greitị, kai nelyja.

\section{Išvados}

1. Kauno ir Vilniaus miestuose vidutinis vèjo greitis lietui lyjant yra apie $25 \%$ didesnis už vẻjo greiti, kai nelyja. Tuo tarpu Klaipèdoje vidutinis vẻjo greitis padidèja nuo $3,59 \mathrm{~m} / \mathrm{s}$, kai nelyja, iki $5,12 \mathrm{~m} / \mathrm{s}$, kai lyja, t. y. apie $40 \%$.

2. Lietui lyjant Klaipedoje dažniausiai pučia vakaru krypties vẻjai, tačiau stipriausi yra pietvakarių vèjai. Lyginant skirtingụ krypčių vidutinius vèjo greičius lietui lyjant ir kai nelyja, didžiausias skirtumas gautas pučiant pietvakarių krypties vẻjams. Jiems pučiant vidutinis vẻjo greitis, kai nelijo, siekè $4,6 \mathrm{~m} / \mathrm{s}$, o lyjant lietui $6,35 \mathrm{~m} / \mathrm{s}$. Vejo greitis lyjant yra apie $38 \%$ didesnis už vẻjo greiti, kai nelyja. 
3. Išanalizavę Klaipèdos miesto vẻjo greičiu skirtumus skirtingais mėnesiais gavome, kad didžiausias vẻjo greičiu skirtumas lietui lyjant ir kai nelyja gautas kovo mènesi, jis siekè $60 \%$.

4. Sudarant klimatologines statybos normas tikslinga ịvertinti vèjo greičio padidejjimą lietui lyjant.

\section{Literatūra}

1. V. Barkauskas, V. Stankevičius. Pastatu atitvaru šiluminè fizika. Kaunas: Technologija, 2000. 286 p.

2. И. Беспрозванная и др. Воздействие ветра на высокие сплошностенчатые сооружения. Москва: Стройиздат, 1976. $184 \mathrm{c}$.

3. Э. Симиу, Р. Сканлан. Воздействие ветра на здания и сооружения. Москва: Стройиздат, 1984. 358 с.

4. V. Paukštys. Lietaus su veju poveikis pastatụ išorinių sienų apsauginés apdailos sienutės drégminiam būviui // Statyba, VI tomas, Nr. 4. Vilnius: Technika, 2000, p. 268-271.

5. Statybiné klimatologija. RSN 156-94 / Lietuvos Respublikos Statybos ir urbanistikos ministerija. Vilnius, 1995. $136 \mathrm{p}$.

Iteikta 20001108

\section{THE ANALYSIS OF SPEED AND PRESSURE OF WIND IN RAINY WEATHER}

\section{Paukštys, V. Stankevičius}

\section{Summary}

It is not enough to investigate only the effect of wind on buildings, because deterioration of exterior surfaces of buildings is caused by wind and moisture together. A considerable part of rain gets into the exterior surface of enclosure, penetrates deep down and destroys the material of surface layer. The rain passes through enclosure construction and its surface layer due to wind pressure, through joints of the elements and cracks caused by improper transportation as well as by an inaccurate assembling.
At present, new multilayer constructional elements are used for building envelope having numerous assembling seams, therefore, the combined influence of rain and wind becomes rather dangerous.

It was established that the wind velocity during the rain is one of the main reasons predetermining moisture penetration into protective-decorative walls made of sand-lime brick with split surface, on concrete-lime mortar, according to the analysis of combined influence of the climate by research data [4]. The total effect of rain and wind on the humidity condition of exterior layers is described.

Distribution of real wind velocity was estimated according to the data of the last 10 years. It was found that in Kaunas the average wind velocity increases from $3,4 \mathrm{~m} / \mathrm{s}$ when the rain is absent up to $4,3 \mathrm{~m} / \mathrm{s}$ and in Vilnius - the average wind velocity increases from $2,9 \mathrm{~m} / \mathrm{s}$ when the rain is absent up to $3,7 \mathrm{~m} / \mathrm{s}$ with an increase of approximately $26 \%$, while in Klaipeda the average wind velocity increases from $3,6 \mathrm{~m} / \mathrm{s}$ when the rain is absent up to $5,1 \mathrm{~m} / \mathrm{s}$ with an increase of approximately $42 \%$.

On the base of the investigations carried out the suggestion is proposed to use the maximum and mean wind velocity values at the rain for estimating the effect of wind to the moisture behaviour in building elements

Valdas PAUKŠTYS. Postgraduate. Kaunas University of Technology (KTU), Faculty of Civil Engineering and Architecture, Dept of Building Materials, Studentu g. 48, LT-3028 Kaunas, Lithuania. E-mail:silfiz@asi.lt

A graduate of KTU, 1995. Research interests: moisture penetration into building constructions, type approval of building construction.

Vytautas STANKEVIČıUS. Doctor Habil, Professor. Institute of Architecture and Construction (IAC), Tunelio g. 60, LT-3035 Kaunas, Lithuania. E-mail: silfiz@asi.lt

Senior Researcher (1964-68), since 1968 - head of Thermal Building Physics Laboratory (IAC). Doctor (1966), Doctor Habil (1991). Professor (1995). Expert member of Lithuanian Academy of Sciences. Author of 182 papers, 3 patents, 2 monographs, 2 study guides, 15 building normative documents. 